\title{
HAK-HAK SUAMI DALAM TEKS-TEKS RELIGIUS DAN DISHARMONI MODERNITAS
}

\author{
${ }^{1}$ Ma'rifatul Munjiah, dan ${ }^{2} Y u s t i$ Rohmatul Hidayah \\ ${ }^{1}$ BSA UIN Maulana Malik Ibrahim Malang, \\ 2al-Akhwalul al-Syakhsiyyah UIN Maulana Malik Ibrahim Malang \\ ${ }_{1}^{1}$ munjiah@bsa.uin-malang.ac.id
}

\begin{abstract}
This study aims to investigate the validity of the sanad and matan hadith and its law implication about husband's right in religiousity texts and modern disharmonity. This study is a qualitative research. The technique of data collection is a search of the literature data, either in the form of data sources primary, secondary or even data that is tertiary. Then the data is understood by using an-naqd ad-dakhili and an-naqd al-khariji to see the validity of the hadith of the husband's right in religiousity text and modern disharmonity. The result of this study is the based on an-naqd al-khariji, the hadith is dhaeef because the transmition is swtiching off; and based on an-naqd ad-dakhili is the hadith is dhaeef because it is contended with the concept muasyarah bil ma'ruf that emphazises the existance of meaning and agreement in relation with good husband - wive in biological and non biological needs.
\end{abstract}

Keywords: husband's right, religious texts, sanad, matan, implication

\section{Abstrak}

Penelitian ini bertujuan untuk menyelidiki validitas hadis sanad dan matan serta implikasi hukumnya tentang hak suami dalam teks agama dan ketidakharmonisan modern. Penelitian ini adalah penelitian kualitatif. Teknik pengumpulan data adalah pencarian data literatur, baik berupa sumber data primer, sekunder atau bahkan data yang tersier. Kemudian data dipahami dengan menggunakan an-naqd ad-dakhili dan an-naqd al-khariji untuk melihat validitas hadis hak suami dalam teks agama dan ketidakharmonisan modern. Hasil dari penelitian ini adalah berdasarkan pada an-naqd al-khariji, hadits adalah dhaeef karena transmisinya sedang dimatikan; dan berdasarkan pada an-naqd addakhili adalah hadits adalah dhaeef karena bertentangan dengan konsep muasyarah bil ma'ruf yang menekankan keberadaan makna dan kesepakatan dalam kaitannya dengan suami yang baik - yang hidup dalam kebutuhan biologis dan non biologis.

Kata kunci: hak suami, teks agama, sanad, matan, implikasi

\section{MUKADDIMAH}

Berawal dari munculnya tuduhan terhadap hadis-hadis pemenuhan kebutuhan biologis suami dalam kitab-kitab klasik yang dikaji di mayoritas pesantren di seluruh Indonesia, seperti yang termaktub dalam kitab Uqud al-Lujain karya al-Nawawi al-Banteni, atau dalam kitab Qurra al-Uyun karya al-Tihami, sebagai hadis palsu (Forum Kajian Kitab Kuning dikutip dalam LBM- 
P2L, 2006, p. 5) dengan indikasi yang nampak pada teks hadis (Yuslem, 2001), artikel ini ditulis sebagai bentuk kontribusi keilmuan yang ilmiah.

Seperti hadis yang menyatakan bahwa seorang istri tidak diperkenankan menolak ajakan suaminya untuk berhubungan badan meskipun dia sedang berada di atas punggung unta. Konteks hadis ini mengarah pada pemahaman bahwa dalam kondisi apapun, seorang istri wajib memenuhi ajakan suaminya. Redaksi hadis yang jika diterjemahkan "meskipun dia sedang berada di atas punggung unta" menuai protes dari mayoritas wanita, terutama yang berprofesi sebagai wanita karier dan juga kelompok-kelompok yang menamakan dirinya pembela hak-hak wanita (Muhammad, 2002).

Terlepas dari benar tidaknya tuduhan palsu terhadap hadis di atas, secara tekstual isi hadis tersebut memang sulit diaplikasikan 100\%, terutama bagi kalangan ibu rumah tangga yang sekaligus sebagai wanita karier. Pasalnya, harus pandai-pandai membagi waktu antara suami, anak, pekerjaan rumah dan karier, agar berjalan seiring. Suatu hal yang sangat melelahkan jika semua itu harus dijalani sendiri dan tanpa pengertian suami untuk meringankan beban istri tiap harinya. Dengan segudang kesibukan dan lelah pada akhirnya, tak jarang para istri sekaligus ibu dan wanita karir menolak ajakan suami untuk berhubungan badan. Meskipun terkadang suami memaklumi, tapi rasa bersalah dan was-was tentu ada saat menolak ajakan tersebut. Bagaimana jika karena suatu hal, seorang istri tidak mampu memenuhi ajakan suaminya? Apa dia akan dilaknat Allah? Atau dibelenggu dan dikumpulkan dengan para setan di neraka paling bawah?

Maka agar tidak terjebak dalam arus tuduhan 'hadis palsu' tanpa memahami dasar hukumnya atau tertekan karena rasa bersalah dan was-was sebab sudah melakukan dosa besar akibat menunda atau menolak permintaan suami maka perlu dilakukan telaah ilmiah terhadap hadis-hadis tentang pemenuhan kebutuhan biologis suami. Dan dalam tulisan ini hadis yang dijadikan sampel adalah hadis yang ada dalam kitab 'Uqud al-Lujain'. Karena kitab ini dipandang sebagai al-kutub al-mu'tabarah, menjadi bacaan utama dan dikaji berulang-ulang di seluruh pesantren di Indonesia.

Martin Van Bruinisen, seorang profesor Belanda pernah melakukan penelitian di 46 pesantren di Indonesia, hasilnya mengindikasikan bahwa 'Uqud al-Lujain menjadi salah satu kitab yang paling sering dibaca di samping karangan-karangan al-Nawawi lainnya (Muhammad, 2002).

Hadis-hadis dalam kitab ini bahkan sering kali dijadikan dalil oleh beberapa da'i dan muballigh dalam dakwahnya untuk melegitimasi gagasan-gagasannya tentang pola hubungan ideal suami istri, padahal hadis-hadis tersebut belum diketahui jelas status dan kualitasnya. 
Kalau memang hadis itu shahih tentu tidak boleh ditolak, bahkan harus diamalkan sebagai dalil syara'. Namun bila hadis itu ternyata dha'if, tidak jelas asalnya atau bahkan maudhu' akan sangat disayangkan bila digunakan secara sembarangan.

Telaah hadis dilakukan melalui metode takhrij hadis yang lazim disebut dengan kritik sanad dan matan, seseorang akan sampai kepada sumber-sumber asli hadis yang pertama kali disusun oleh para ulama pengkodifikasi hadis. Melalui kaidah-kaidah takhrij pula akan terungkap keragu-raguan dan kekeliruan pada matan hadis (seperti adanya salah cetak), atau peringkasan penulisan matan hadis, atau pemisahan-pemisahan hadis yang matannya panjang. Di samping itu, dengan penelusuran hadis, sanad-sanadnya pun menjadi jelas, baik yang melalui satu jalur ataupun tidak, sehingga diketahui bahwa kualitas suatu hadis telah naik, karena adanya jalur lain yang lebih tinggi yang menguatkannya (Yuslem, 2001).

Seperti diketahui, kualitas sebuah hadis, apakah ia bisa diterima ataukah justru ditolak, dapat ditinjau dari dua sisi, yakni sisi sanad (transmisi), dalam ilmu hadis lazim dikenal dengan al-naqdu al-khariji, dan sisi matan (teks, bunyi) atau disebut juga al-naqdu al-dakhili (Yuslem, 2001). Bahkan tiga dari lima kriteria diterimanya sebuah hadis berhubungan dengan sanad.

Dan untuk mengetahui sumber hadis perlu dilakukan pendekatan nash (teks), dengan menelusuri hadis melalui pendekatan tema, pendekatan lafal pertama matan, atau pendekatan kata dasar yang gharib (asing). Hadis yang tidak dapat ditemukan melalui dua pendekatan ini, dicari sedapatnya melalui kitab hadis lain, seperti kitab hadis yang berisikan hadis-hadis maudhu', karena bisa jadi hadis yang tidak tercantum dalam kitab dengan dua pendekatan di atas adalah maudhu'.

Bila hadis-hadis yang ditelusuri telah ditemukan sumbernya dan menjadi jelas sanadnya, maka dilakukan analisa kualitas. Dalam analisa kualitas dan telaah terhadap matan hadis dengan cara membandingkan matan hadis yang sedang diteliti dengan ayat-ayat alQur'an, dan hadis-hadis lain yang bernilai shahih, dan pendekatan sejarah guna memperoleh kesimpulan mengenai kualitas matan hadis yang tengah diteliti (Sumbulah, 2008). Dan langkah terakhir adalah menelaah implikasi hukumnya.

Dalam artikel ini, hadis di ataslah yang akan dianalisa kualitasnya, baik dari sisi sanad maupun matannya, selanjutnya implikasi hukumnya juga diulas.

\section{KRITIK SANAD DAN IMPLIKASI HUKUMNYA}

Sebelum analisa kualitas dilakukan sangat penting kiranya mengetahui kriteria keshahihan suatu hadis. 
Agar sebuah hadis bisa diterima dan boleh dijadikan sebagai upaya legal formal (hujjah/dalil), maka harus memenuhi lima kriteria yang sudah ditetapkan oleh ulama ahli hadis, yaitu:

a. Sanadnya bersambung, mulai dari Nabi, sahabat, hingga periwayat terakhir

b. Periwayatnya memiliki sifat 'adil

c. Periwayatnya juga memiliki sifat dhabith

d. Informasi hadisnya tidak syadz

e. Hadis yang diriwayatkan tidak bercacad

Para ulama sependapat bahwa hadis shahih harus memenuhi persyaratan di atas, karena kesemuanya adalah standarisasi hadis shahih, dan bila semua syarat sudah terpenuhi, maka hadis tersebut dinamai shahih lidzatih.

Berikut adalah analisa sanad dari hadis kewajiban memenuhi kebutuhan biologis suami dalam kondisi apapun, yang secara lengkap berbunyi:

$$
\text { أن المر أة لاتؤدي حق الله تعالى حتى تؤدي حق زوجها كله لو سألها وهي على ظهر قتب لم تمنعه نفسها }
$$

"Bahwasannya wanita itu tidak dapat memenuhi hak Allah sebelum memenuhi hak-hak suaminya. Andaikan suami meminta kepada istrinya sementara sang istri sedang berada di atas punggung unta maka ia harus menyerahkan dirinya" (Al Nawawi, n.d.).

Ketika hadis di atas ditelusuri melalui pendekatan tema dan lafal pertama hadis hanya ditemukan satu catatan, yaitu hadis itu berasal dari Zaid bin Arqam dan diriwayatkan oleh alThabrani dengan isnad jayyid (jalur periwayatan yang bagus). Dan ketika ditelusuri dalam kitab al-Mu'jam al-Kabir karya Thabrani ditemukan dengan redaksi sebagai berikut:

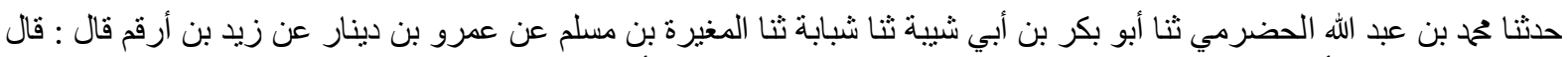

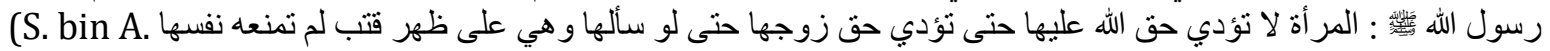
bin A. Al Thabrani, 1983, vol. I, p. 200)

Hadis di atas diriwayatkan oleh Al-Thabrani, dari Muhammad bin 'Abdullah alHadhrami, dari Abu Bakar bin Abi Syaibah, dari Syubabah, dari al-Mughirah bin Muslim, dari 'Amr bin Dinar, dari Zaid bin Arqam, dari Nabi SAW.

Berikut adalah riwayat para transmiter hadis berikut kualitasnya.

\section{a] Zaid bin Arqam}

Nama lengkapnya adalah Zaid bin Arqam bin Zaid bin Qais bin al-Nu'man bin Malik bin al-Aghar bin Tsa'labah bin Ka'ab bin al-Khazraj al-Anshari (w. Tahun 66 H) ('Izzuddin, n.d., vol. I, p. 391).

Hubungan periwayatan Zaid bin Arqam dengan Rasulullah sebagai sumber hadis tidak perlu diragukan. Dalam kitab Usdu al-Ghabah disebutkan bahwa keterikatan Zaid bin Arqam 
dengan Rasul bisa disaksikan melalui kedekatan keduanya. Zaid telah menemani Rasul dalam 17 ghazwah.

Kualitas Zaid bin Arqam sebagai orang yang jujur, adil, dan kata-katanya bisa dipertanggung jawabkan tidak hanya diakui kalangan sahabat dan para kritikus hadis. Allah sendiri mengakui sifat Zaid bin Arqam tersebut dengan menurunkan bukti pembenar atas kebenaran perkataan Zaid bin Arqam melalui salah satu ayat dari surat al-Munafiqun ('Izzuddin, n.d., vol. I, p.392).

Dalam buku rijal al-hadis disebutkan orang-orang yang menerima hadis dari Zaid bin Arqam adalah Anas bin Malik, 'Abu Khair al-Hamdani, Abu Ishaq al-Sabi'i, Muhammad bin Ka'ab al-Quradli, Thawus, Abu Hamzah, dan lainnya (Al 'Asqalani, n.d., vol. III, p. 340) .

Dalam deretan nama tersebut, nama 'Amr bin Dinar tidak disebutkan secara eksplisit. Kata-kata wa ghairuhum (dan lainnya) tidak bisa dijadikan bukti adanya hubungan periwayatan antara Zaid bin Arqam dengan 'Amr bin Dinar. Namun bila dalam riwayat hidup 'Amr bin Dinar terdapat nama Zaid bin Arqam sebagai orang yang pernah mentransfer hadis kepadanya, maka hubungan sanad antara keduanya dinyatakan ittishal (bersambung).

\section{b] 'Amr bin Dinar}

'Amr bin Dinar yang dimaksud adalah 'Amr bin Dinar al-Makki, Abu Muhammad alAtsram al-Jumahi (w. tahun 126 H) (Al 'Asqalani, n.d., vol. I, p. 734).

Ia meriwayatkan hadis dari Ibn 'Abbas, Abu al-Minhal, 'Abdurrahman bin Muth'im, 'Urwah bin Zubair, dan jama'atun (masih banyak yang lain) (Al 'Asqalani, n.d., vol. VIII, p.26).

Dalam riwayat guru-guru 'Amr bin Dinar juga tidak ditemukan nama Zaid bin Arqam sebagai orang yang pernah meriwayatkan hadis kepadanya. Kata jama'atun tidak bisa dijadikan landasan untuk menetapkan sebuah pernyataan posibilitas -mungkin di antara nama yang tidak tersebut terdapat nama Zaid bin Arqam-. Oleh karena itu berpijak pada data yang ada, bisa disimpulkan bahwa transmisi hadis dari Zaid bin Arqam kepada 'Amr bin Dinar tidak bersambung.

Sebagai seorang perawi hadis, kualitas 'Amr bin Dinar sangat diakui para kritikus hadis. Nu'aim bin Hammad meriwayatkan dari Ibn 'Uyainah: "Satu hadis yang aku dengar dari 'Amr bin Dinar lebih aku sukai daripada dua puluh hadis yang kudengar dari lainnya". 'Abdurrahman menilainya dengan tsiqah-tsiqah.

\section{c] Al-Mughirah bin Muslim}


Nama lengkapnya adalah Al-Mughirah bin Muslim al-Qasmali, Abu Salamah al-Sarraj. Tidak ada informasi pasti mengenai tahun wafatnya. Al-'Asqalani hanya menyebutkan ia termasuk generasi ke enam (min al-sadisah) (Al 'Asqalani, n.d., vol. II, p. 208), yang berarti wafatnya setelah tahun $100 \mathrm{H}$ (Al 'Asqalani, n.d., vol. I, p. 26).

Ia menerima hadis dari 'Ikrimah, 'Abdullah bin Buraid, Abi Ishaq al-Sabi'i, Abi Zubair alMakki, Yunus bin 'Ubaid, 'Amr bin Dinar (Al 'Asqalani, n.d., vol. X, p. 240).

Dari data tersebut diketahui adanya hubungan periwayatan antara 'Amr bin Dinar dengan al-Mughirah bin Muslim. Ini artinya, transmisi mereka bersambung.

Al-Mughirah bin Muslim sendiri menyampaikan hadis kepada al-Tsauri, Marwan bin Mu'awiyah al-Fazari, Abu Dawud al-Thayalisi, Syubabah bin Sawwar, Asbath bin Muhammad alQurasyi, dan masih banyak lagi (Al 'Asqalani, n.d., vol. X, p. 240).

Data di atas menunjukkan adanya transmisi ke bawah antara al-Mughirah bin Muslim dengan Syababah bin Sawwar, yang ini menjadi indikator ketersambungan sanad.

Penilaian beberapa kritikus hadis terhadap Al-Mughirah bin Muslim sangat positif dengan tingkat tsiqah menengah, walaupun terminologi yang digunakan berbeda-beda (Al Razi, n.d., vol. VIII, p. 229).

\section{d] Syubabah bin Sawwar}

Nama lengkapnya adalah Syubabah bin Sawwar al-Fazari al-Madaini (w. tahun 204 H) (Al Razi, n.d., vol. IV, p. 392). Syubabah meriwayatkan hadis dari Hariz bin 'Utsman al-Rahbi, Syu'bah, Syaiban, al-Mughirah bin Muslim, al-Laits, dan lainnya(Al 'Asqalani, n.d., vol. IV, P. 264).

Data ini memperlihatkan adanya ittishal al-sanad antara Syubabah dan al-Mughirah bin Muslim.

Di antara muridnya adalah Syubabah 'Utsman bin Abi Syaibah, Abu Bakar bin Abi Syaibah, Abu Khaitsamah, Zuhair bin Harb, Hajjaj bin Hamzah (Al Razi, n.d., vol. IV, P. 392).

Nampaknya kebersambungan sanad juga ada dalam riwayat tersebut karena Abu Bakar bin Abi Syaibah disebutkan secara jelas sebagai muridnya.

Zakariya al-Saji dan Ibn Kharrasy menyebutnya shaduq fi al-hadis. Ja'far al-Thayalisi memberinya nilai tsiqah. Abu Hatim menyebutnya shaduq dan menulis hadis darinya, namun ia tidak menggunakan hadis riwayat Syubabah tersebut sebagai hujjah. 'Ali bin al-Madini menilai, terkadang dalam hapalan Syubabah ada kekeliruan(Al 'Asqalani, n.d., vol. IV, p. 265).

\section{e] Abu Bakar bin Abi Syaibah}

Menurut al-'Asqalani, namanya adalah 'Abdullah bin Muhammad bin Ibrahim (Abi Syaibah) bin 'Utsman, al-Kufi (w. tahun 235 H) (Al ’Asqalani, n.d., vol. I, p. 528). 
Abu Bakar bin Abi syaibah meriwayatkan hadis dari Abi al-Ahwash, Ibn Mubarak, Abi Bakar bin 'Ayyasy, Isma'il bin 'Ayyasy, Muhammad bin Fudhail, dan lainnya (jama'atun) (Al 'Asqalani, n.d., vol. VI, p. 3).

Dalam deretan nama orang yang meriwayatkan hadis kepada Abu Bakar bin Abi syaibah tidak disebutkan nama Syubabah. Namun hal ini tidak menafikan adanya transmisi antara keduanya karena dalam riwayat Syubabah nama Abu Bakar bin Abi Syaibah tertulis sebagai muridnya.

Adapun murid-muridnya adalah al-Bukhari, Muslim, Abu Dawud, Ibn Majah, 'Utsman bin Kharzadz, Ahmad bin Hanbal dan Putranya, al-Haitsam bin Khalaf al-Dauri, Abu al-Qasim alBaghawi, dan lainnya (Al 'Asqalani, n.d., vol. VI, p. 3).

Memang dalam daftar orang-orang yang menerima hadis dari Abu Bakar bin Abi Syaibah tidak ada nama Muhammad bin 'Abdullah al-Hadhrami yang menjadi sanad pertama yang selanjutnya mentransfer hadis kepada Mukharrij, al-Thabrani. Sehingga data yang ada mengindikasikan tidak bersambungnya sanad antara Abu Bakar bin Abi Syaibah dengan alHadhrami.

Sebagai seorang perawi, eksistensi Abu Bakar bin Abi Syaibah diakui kalangan muhadditsin. Ahmad bin Hanbal mengatakan: "ia shaduq". Al-'Ajali menyebutnya tsiqah dan hafidl. Amr bin Ali mengakui daya ingat Abu Bakar yang di atas rata-rata (Al 'Asqalani, n.d., vol. VI, p. 4). Pendapat-pendapat para tokoh hadis ini cukup menjadi bukti kualitas Abu Bakar bin Abi Syaibah.

\section{f] Muhammad bin 'Abdullah al-Hadhrami}

Dari sekian banyak nama Muhammad bin 'Abdullah, hanya ada satu yang dinisbahkan pada kota Hadhramut. Yaitu Muhammad bin 'Abdullah bin Sulaiman al-Hadhrami (Al Razi, n.d., vol. VII, p.298), Dalam biografinya tidak disebutkan tahun wafat ataupun tahun kelahirannya.

Dalam riwayat guru-gurunya pun tidak ada nama Abu Bakar bin Abi Syaibah, sehingga hubungan sanad dari sisi atas, antara Muhammad bin 'Abdullah al-Hadhrami dengan gurunya, Abu Bakar bin Abi Syaibah, dinilai tidak bersambung.

Menurut al-Razi, guru-guru al-Hadhrami adalah 'Ali bin Hakim al-Audi, Ahmad bin Yunus, 'Abdul Hamid Shalih, 'Ubaid ibn Ya'isy, al-Haitsam bin 'Ubaidillah al-Qurasyi, dan Yahya bin Bisyir al-Hariri. Al-Razi juga menyebutnya shaduq, sebagai indikasi penilaian positif (Al Razi, n.d., vol. VII, p.298).

Dalam deretan perawi jalur al-Thabrani sebelumnya dijelaskan bahwa al-Thabrani menerima hadis dari Muhammad bin 'Abdullah al-Hadhrami. Tapi dalam riwayat murid al- 
Hadhrami nama al-Thabrani tidak disebutkan. Hal ini mengindikasikan hubungan sanad antara al-Hadhrami dengan al-Thabrani tidak bersambung.

\section{g] Al-Thabrani}

Namanya adalah Sulaiman bin Ahmad bin Ayyub bin Mathar, Abu al-Qasim al-Thabrani (w. tahun 360 H) ('Asakir, n.d., vol. XXII, p. 163).

Beberapa gurunya adalah Abu Zur'ah, Ahmad bin Anas bin Malik, Yahya bin Ayyub al'Allaf, Ishaq bin Ibrahim al-Dubari, Aba Zaid Ahmad al-Hauthi, dan masih banyak lagi gurunya. Namun dari sekian banyak orang yang meriwayatan hadis kepadanya, tidak terdapat nama alHadhrami sebagai guru al-Thabrani ('Asakir, n.d., vol. XXII, p. 163). Dari data ini disimpulkan bahwa ittishal al-sanad yang menjadi salah satu syarat hadis shahih tidak terpenuhi.

Kapasitas al-Thabrani sebagai seorang perawi sekaligus mukharrij, diakui oleh banyak kalangan. Ibn 'Asakir menyebutnya ahad al-huffadl al-mukassirin wa al-rahhalin fi al-hadis (petualang hadis yang hafidl dan banyak meriwayatkan hadis). Abu Bakar bin Abi 'Ali memujinya sebagai perawi hadis yang spektakuler ('Asakir, n.d., vol. XXII, p. 165). Komentar tersebut menunjukkan kualifikasi al-Thabrani sebagai seorang perawi yang tsiqah.

Uraian di atas menunjukkan adanya transmisi yang terputus yaitu antara 'Amr bin Dinar dengan gurunya, Zaid bin Arqam, dan antara al-Hadhrami dengan Ibn Abi Syaibah (guru) dan alHadhrami dengan al-Thabrani (murid).

Hadis yang tidak memenuhi salah satu dari lima syarat hadis shahih dihukumi dha'if. Namun demikian hadis riwayat al-Thabrani di atas berstatus marfu', karena disandarkan langsung kepada Rasul.

Sebuah hadis dikategorikan shahih apabila ia bersambung sanadnya, perawinya adil dan dhabit, hadisnya tidak syadz dan tidak ber'illat. Syarat pertama, bersambung sanadnya tidak dipenuhi oleh hadis riwayat al-Thabrani ini. Syarat ke dua dan ke tiga, adil dan dhabit yang biasanya digabung menjadi tsiqah, bila melihat kualitas para perawi di atas dapat disimpulkan sudah terpenuhi meskipun tingkat ke-tsiqah-annya bervariasi. Adapun mengenai analisa kesyadz-an atau tidaknya sebuah hadis (syarat no 4) tidak bisa diterapkan di sini, karena penentuan syadz tersebut dilakukan jika sebuah hadis memiliki lebih dari satu sanad dan para periwayat hadis itu seluruhnya tsiqah, namun matan atau sanadnya bertentangan (Katsir, 1999). Sedangkan hadis ini, berdasar penelusuran hanya ditemukan pada satu sumber yaitu dalam riwayat al-Thabrani dengan hanya satu jalur, sehingga upaya membandingkannya dengan riwayat lain tidak mungkin dilaksanakan, dan syarat terakhir, hadisnya tidak cacat (Yuslem, 2001) sudah terpenuhi dalam riwayat al-Thabrani ini. 
Dari uraian di atas disimpulkan bahwa hadis riwayat al-Thabrani ini adalah dhaif karena beberapa syarat keshahihan hadis tidak terpenuhi. Jika demikian adanya, hadis isi tidak dapat digunakan sebagai hujjah atau dalil terlebih jika digunakan untuk menjustifikasi suatu perbuatan.

\section{KRITIK MATAN DAN IMPLIKASI HUKUMNYA}

Seperti halnya sanad yang memiliki kriteria keshahihan, matan juga memiliki kriteria keshahihan. Kriteria kesahihan matan hadis menurut muhaddisîn beragam. Perbedaan latar belakang, keahlian, alat bantu, persoalan, dan masyarakat yang dihadapi oleh mereka turut mempengaruhi keragaman tersebut. Bustami berupaya merangkumnya sebagai berikut: pertama, tidak bertentangan dengan al-Qur'an; kedua, tidak bertentangan dengan hadis mutawattir atau hadis ahad yang sahih; ketiga, sejalan dengan akal sehat; keempat, tidak bertentangan dengan sejarah; dan kelima, susunan pernyataannya menunjukkan ciri-ciri kenabian (M. Isa, 2004). Dari lima kriteria tersebut, artikel ini akan mengupas syarat pertama dan kedua.

a. Pendekatan al-Qur'an

Secara spesifik tidak ada ayat yang menyebutkan seorang istri wajib memenuhi kebutuhan biologis suami, baik itu yang bersifat harus bersegera maupun larangan menolak ajakan suami dan semacamnya. Namun ada satu ayat yang secara global mencakup segala kepatuhan istri terhadap suami. Ayat tersebut adalah Q.S. An-Nisa' ayat 34;

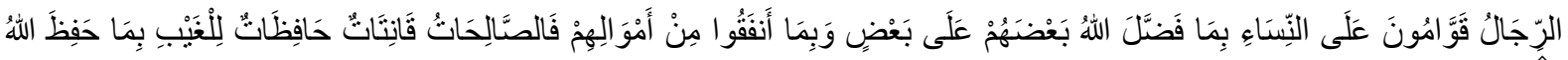

" Kaum laki-laki itu adalah pemimpin bagi kaum wanita. Sebab, Allah telah melebihkan sebagian mereka (laki-laki) atas sebagian yang lain (wanita), dan karena mereka (lakilaki) telah menafkahkan sebagian dari harta-harta mereka. Oleh karena itu, wanitawanita yang salih ialah yang menaati Allah lagi memelihara diri di belakang suaminya karena Allah telah memelihara (mereka)".

Dalam tafsir Ibnu Katsir dikemukakan bahwa yang dimaksud dengan lafadz qawwam pada ayat tersebut adalah dengan segala kelebihan yang dimiliki pria dibanding wanita, seorang pria adalah kepala sekaligus pemimpin dan hakim serta pendidik bagi wanita (Katsir, 1999, vol. I, p. 84). Karenanya seorang istri wajib mentaati segala perintah suaminya (termasuk juga dalam hal hubungan biologis, tidak boleh menolak saat suami menginginkan) dan menjaga nama baik serta hartanya saat suami tidak ada. 
Ayat di atas sifatnya masih 'am (umum), karena ada lagi ayat yang lebih khas (khusus) memerintahkan untuk menggauli istri dengan ma'ruf (baik).

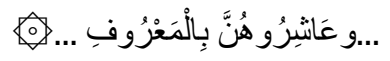

"Dan bergaullah kalian (para suami) dengan mereka (para istri) secara patut." (alNisa':19)

Abu Ja'far berkata terkait ayat di atas, makna lafadz وَعَانثِرُو هُنَّ بِالْمَرُرُوفِ adalah menjadikan istri sebagai sahabat, dan jagalah mereka dengan memenuhi hak-hak mereka (A. J. Al Thabrani, 2000, vol. I, p. 80), karenanya istri juga memiliki hak untuk berpendapat dan mengungkapkan keinginannya termasuk dalam hal hubungan badan.

Konsep mu'asyarah bil ma'ruf menuntut adanya kebersamaan menyangkut segala kebutuhan suami-isteri. Termasuk menyangkut hubungan seksual antara mereka berdua. Adalah bukan mu'asyarah bil ma'ruf' jika hubungan badan hanya menyenangkan satu pihak, sementara pihak lain tersakiti. Pola relasi antara suami dan istri yang ditegaskan al-Qur'an adalah setara. Sebagaimana firman Allah SWT;

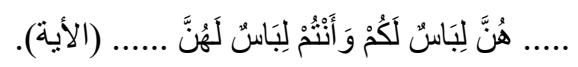
"perempuan adalah pakaian bagi laki-laki, dan laki-laki adalah pakaian bagi perempuan". (Al-Baqarah :187)

Dari uraian di atas peneliti menyimpulkan bahwa matan hadis pemenuhan kebutuhan biologis suami di atas berkualitas dha'if karena tidak sejalan dengan semangat al-Qur'an. Di mana pesan hadis tersebut adalah seorang istri wajib memenuhi kebutuhan biologis suami tanpa perlu mempertimbangkan kondisi istri sedang pesan yang disampaikan al-Qur'an melalui konsep mu'asyarah bil ma'ruf adalah pengertian dan kerelaan kedua pihak.

b. Pendekatan hadis shahih

Dalam analisa sanad disebutkan bahwa hadis tentang 'kewajiban istri memenuhi kebutuhan biologis suami dalam kondisi apapun' hanya memiliki satu jalur yaitu al-Thabrani, dan dari sisi kualitas dinyatakan dhaif karena beberapa transmisinya terputus. Itu artinya, tidak ada hadis lain yang secara tekstual bisa dijadikan pembanding melalui pintu ini. Namun dalam konteks yang lebih luas terdapat hadis riwayat Bukhari dan Muslim yang bisa dijadikan pertimbangan. Yaitu hadis yang berbunyi;

$$
\text { عن أبي هريرة قال فال النبي }
$$

Artinya: dari Abu Hurairah ra. berkata, Nabi saw bersabda, "Jika seorang istri menghabiskan malam dengan meninggalkan tempat tidur suaminya maka para malaikat melaknatnya hingga ia kembali".(Al Bukhari, n.d., vol. III, p. 260).

Hadis ini memang tidak secara spesifik menyebutkan klausul "meskipun di atas punggung unta" seperti hadis riwayat Thabrani, namun ada ulama yang mengatakan bahwa konteks hadis riwayat Bukhari dan Thabrani adalah sama, yaitu terkait kebutuhan biologis 
suami. Ada pula ulama yang menolaknya, meski secara garis besar konteksnya sama namun tujuan berbeda.

Pada akhirnya, perbedaan sudut pandang ini melahirkan perbedaan implikasi hukum, jika merunut pada pendapat pertama maka kualitas matan hadis Thabrani ini adalah shahih, karena ada hadis lain yang menguatkannya. Tapi jika merujuk pada pendapat kedua maka kualitasnya adalah dhaif, karena kriteria keshahihannya tidak terpenuhi.

\section{PENUTUP}

Berpijak pada uraian di atas maka hadis yang berbunyi:

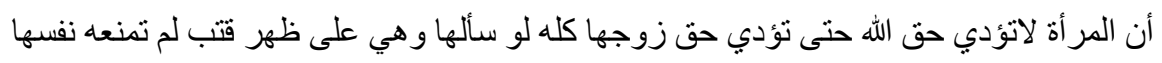
yang sering kali digunakan sebagai upaya legal formal untuk menjustifikasi kewajiban istri memenuhi kebutuhan biologis suami dalam kondisi apapun, yang ada dalam kitab Uqud alLujain berdasarkan penelusuran pada sumber aslinya adalah riwayat al-Thabrani. Dan setelah dilakukan kritik sanad diperoleh kesimpulan bahwa dari sisi sanad hadis tersebut masuk kategori dhaif karena ada transmisi hadis yang terputus, dan bukan hadis maudhu (palsu). Sedang ketika ditelaah matannya melalui pendekatan al-Qur'an didapati bahwa hadis ini juga dhaif karena tidak sejalan dengan konsep muasyarah bil ma'ruf yang menekankan adanya pengertian dan kerelaan dalam relasi suami istri baik dalam kebutuhan biologis maupun non biologis. Adapun telaah matan dengan pendekatan hadis shahih memberikan simpulan dhaif jika mengacu pada pendapat ulama yang berbasis tujuan teks bukan konteks umum hadis.

Ini artinya, hadis riwayat al-Thabrani ini baik dari sisi sanad maupun matan dihukumi dhaif dan implikasinya, hadis yang dhaif tidak boleh digunakan sebagai hujjah dengan mengacu pada pendapat mayoritas ulama ahli hadis, karena syarat diperbolehkannya hadis dijadikan hujjah adalah bila dia berstatus shahih.

\section{DAFTAR PUSTAKA}

'Izzuddin. (n.d.). Usdu al-Ghabah fi ma'rifat al-shahabah.

'Asakir, I. (n.d.). Tarikh Dimasyqa. Beirut: Dar al-Fikri.

Al 'Asqalani. (n.d.). Taqrib al-tahdzib.

Al Bukhari, M. bin I. (n.d.). Shahih bukhari. Dar al-Fikri. 
Al Nawawi, M. bin 'Umar. (n.d.). 'Uqud al-lujain fi bayani huquq al-zujain. Dar Ihya' al-Kutub al'Arabiyah.

Al Razi. (n.d.). al-Jarh wa al-Ta'dil.

Al Thabrani, A. J. (2000). Jami' al-bayan fi ta'wil al-Qur'an. Mu'assasah al-Risalah.

Al Thabrani, S. bin A. bin A. (1983). Al-mu'jam al-kabir. Maktabah al-'Ulum wa al-Hikam.

Katsir, I. (1999). Tafsir al-Qur'an al-'Adhim. Dar Thayyibah Linnasr wa Tauzi'.

LBM-P2L. (2006). Potret ideal hubungan suami istri. Kediri: Madrasah Hidayatul Mubtadiin, LBM-P2L.

M. Isa, B. (2004). Metodologi kritik hadis. Jakarta: PT. Raja Gravindo Persada.

Muhammad, H. (2002). Fiqh perempuan: Refleksi kiai atas wacana agama dan gender. Yogyakarta.

Sumbulah, U. (2008). Kritik hadis dengan pendekatan historis metodologis. Malang: UIN Press.

Yuslem, N. (2001). Ulumul Hadis. Mutiara Sumber Widya. 